Anthropol. Sci. 102(1), 49-57, 1994

\title{
Genealogical-Demographic Analysis of the Long-term Adaptation of a Human Population: Methodological Implications
}

\author{
RYUTARO OHTSUKA \\ Department of Human Ecology, Faculty of Medicine, \\ The University of Tokyo, Hongo, Tokyo 113, Japan
}

Received December 18, 1992

\begin{abstract}
One of the goals of ecological anthropology and/or human ecology is to elucidate the long-term survival mechanisms of a human population as a whole. This paper discusses methedological issues, centering on a genealogy-based method for estimating reproduction rates and population increase rates in the past, which I have applied to the Gidra and some other populations in Papua New Guinea. Depending on the sociocultural circumstances of the target populations, the applicability and validity of this method vary; in some cases, these rates can be estimated to a satisfactory degree, and thus contribute from quantifiable evidence to reconstructing a population's ethnohistory and its relationships with diversified and changing environmental conditions on the one hand, and to clarifying gene frequency patterns on the other hand.
\end{abstract}

Key Words: population ecology, genealogical demography, long-term adaptation, net reproduction rate, population increase rate

\section{INTRODUCTION}

The basic data of ecological anthropology and/or human ecology are collected by means of observation, measurement, and interviews during field work among, in most cases, small human groups. A unique approach in ecological studies is to integrate various kinds of information for a total understanding of the humanenvironment relationship or human survival. Thus, various research frameworks coexist, even if the final goals are very similar; we have paid special attention to "production," "consumption," and "reproduction" as a set of key concepts (Suzuki and Ohtsuka, 1987).

For clarifying our framework, it is meaningful to operationally characterize various research items and parameters, relevant to the three key concepts, and correlate them with one another. In one effective way I propose here, the items or parameters are categorized according to the time length of observation on the one hand and the organizational level of the human subjects on the other hand. Table 1 demonstrates a simplified two-by-two quadrant model based on these two aspects, in which major items and parameters are plotted.

For the time scale, the "short term" refers to the period within an annual cycle 
Table 1. Principal assessment points for human survival, categorized according to time scale of observation and organizational level of humans

\begin{tabular}{lll}
\hline & Individual & Population \\
\hline Short-term & Food-obtaining & Resource management \\
& Food-consuming & Cooperation \\
& Nutritional state & Food sharing \\
& Health state & Fertility (periodical) \\
& & Mortality (periodical) \\
\hline Long-term/ & Marriage & Ecological versatility \\
Life span & (age, duration) & Technological innovation \\
& Longevity & Reproduction rate \\
& Total childbearings & (inter-generational) \\
& & Population increase rate \\
\hline
\end{tabular}

and the "long term" to the period of a whole human lifespan or over generations; in his methodological discussion of assessing human adaptations in small-scale societies, Ellen (1982) distinguishes the "medium term" within a single life cycle from the "long term" of any longer period.

Regarding the organizational levels of humans, this model denotes only two levels, an individual and a population. Strictly speaking, a human population should refer to human aggregations, which are defined ecologically as the individuals who occupy a bounded geographical region (e.g., Odum, 1971) and genetically as those forming a reproductive unit and thus sharing a common gene pool (e.g., Dobzhansky, 1968). Keeping these notions in mind, however, a population in this model can be applied to smaller-scale aggregations such as a village group or a kin group. In this connection, the characterizations of the structural and functional units of humanenvironment systems are well discussed by many contributors to The Ecosystem Approach in Anthropology: From Concept to Practice edited by Moran (1990); for instance, Rappaport (1990) emphasizes that all levels - i.e., ecosystems, local populations, regional populations, and individuals - share certain indispensable aspects in ecological studies for humans.

The category of "short-term and individual" in this quadrant model includes the items (each can be expressed with several parameters) which have commonly been pursued in subsistence ecology (or cultural ecology), nutritional ecology, and/or health ecology; some basic points for these approaches are discussed elsewhere in this volume by Suda (1994), Kuchikura (1994), and Inaoka (1994). In the category of "short-term and population," two different kinds of items/parameters are involved. The first type, resource management, cooperation, and food sharing, are related to subsistence strategies managed at a population (or sub-population) level; the second type, periodical (usually, annual) fertility and mortality, are popular demographic parameters, although they are seldom meaningful for the study of small 
populations due to their fluctuations by chance.

The items/parameters involved in the quadrant "long-term (life span) and individual" are directly related to fertility and reproduction, even though they depend on social systems on the one hand and nutritional and health states on the other; all of these tend to change owing to, for instance, modernization influences. These items/parameters are usually obtained for living peoples only, so that these data alone are not enough to reconstruct long-term demographic changes (simply because the records of healthy and long-lived individuals among the whole birth cohort are collected in high frequency), despite the fact that they are of great value for many other purposes.

The last quadrant, "long-term and population," with which this paper mainly deals, involves a variety of items/parameters. Ecological versatility, represented by the number of environments in which a population can survive (Ellen, 1982), is considered to possess two meanings: one is concerned with heterogeneous environmental conditions within a single population's territory, for which different adaptive strategies have been developed; the other, in a more positive sense, implies expansion of a population's territory to new environmental zones. The technological innovations, in relation to both implemental and social organizational changes, have taken place with or without the influences of other cultures, including recent modernization.

Both ecological versatility and technological innovation are closely related to long-term demographic change and its intrapopulational variability. Methodologically, it is difficult to arrive at fertility, mortality, and reproduction rates over a long period among the small-scale, and usually nonliterate, populations that have been mostly studied by ecological anthropologists and human ecologists, and that are the target of this paper. My attempt to apply genealogy-based reconstruction of past inter-generational reproduction rates (and population increase rates) has been made to address this difficulty. It is my contention that an understanding of the reproduction and population increase rates in the past will enable us to more precisely grasp the long-term human survival system as a whole; human survival cannot be fully understood without this kind of information.

\section{METHODOLOGICAL BASES FOR MEASURING REPRODUCTION RATES IN THE PAST}

Formal demography has taught us that the net reproduction rate (NRR) - the average number of daughters that would be born to a birth cohort of women during their lifetime if they experienced a fixed pattern of age-specific fertility and mortality rates - provides a measure of the way in which a generation of women replaces itself (Pressat, 1985). Theoretically, when the time length between two generations is given, the increase rate per year $(r)$ can be calculated from the 
$\operatorname{NRR}\left(R_{\mathrm{O}}\right)$ as follows:

$$
r=R_{\mathrm{O}}^{1 / y}-1 \text {, }
$$

where $y$ is the length (in years) between two generations. In practice, the NRR can be calculated from two parameters: the completed fertility, the cumulative fertility at the end of the reproductive ages of mothers, and the death rate of their daughters before the mothers' ages at the deliveries.

To measure fertility in small-scale nonliterate populations, completed fertility is more applicable than the periodical fertilities, which tend to fluctuate. In fact, Nag (1962) applied this indicator for cross-cultural fertility comparisons among nonindustrial societies; however, he used the term "total maternity ratio" instead of "completed fertility." The idea of completed fertility has also been used, for instance, by Howell (1979) in her well-known study among the !Kung San in Kalahari. Nevertheless, the NRR has not been applied to nonliterate populations. The major reason for this seems to be the difficulty of estimating premature mortality rates among daughters. It should also be noted that the completed fertility records do not necessarily indicate the fertility levels of such populations because, as mentioned earlier, the records are collected in higher frequency from the relatively long-lived women.

To estimate the NRR (including the population increase rate) for the past, I introduced a new idea. The methodology has been described in detail elsewhere (Ohtsuka, 1986), so only the essential points will be mentioned here; in the previous papers, the term "daughter-mother ratio" was used for the NRR. In my method, the NRR was calculated based on the number of daughters who survived to marry per mother, using the genealogical records. In order to group the mothers into several "cohorts," they were categorized according to such factors as whether each mother's female offspring had married and whether they had completed childbearing. For estimating the time period between generations, which is needed to calculate the population increase rate, different levels between 20 and 25 years were examined; the estimated increase rates showed minor differences.

\section{APPLICATION TO THE GIDRA-SPEAKING POPULATION}

The genealogy-based estimation of the NRR in the past was first applied to the Gidra-speaking population which has inhabited the lowlands of Papua New Guinea (Fig. 1). Despite the small size of this population - 1,850 de facto in our 1980 census - it is recognized as a biotic population since the people possess their 4000 square kilometer territory and have formed a basic unit of marriages and thus share a common gene pool (e.g., Ohtsuka, 1983; Ohtsuka and Suzuki, 1990, for details).

There are two interrelated social customs of the Gidra that are directly favorable to this study. First, the Gidra have kept their patrilineal totemic clan system: there are about 40 clans, which are grouped into two moieties. Each clan possesses a 
portion of the Gidraland. Particularly important is the fact that the ancestors of each clan, up to three or four generations back, are still well remembered by the present members. Second, marriages have been organized by means of exchange of females between two clans of the different moieties, so that two marriages are arranged simultaneously. This exchange system has occasionally caused imbalances in relations between the clans; this occurred, in particular, when a bride died without bearing children while her counterpart in the marriage exchange bore many children. In such cases, compensation could be claimed by members of one of the clans, but in most cases, this has not been done, and as a result inter-clan conflicts have accumulated; these marriage histories of the ancestors have been the most important "historical" events for each clan and thus are well remembered by its members.

Under such circumstances, my data gathering of the Gidra genealogies for about five months, in total, in 1980 and 1981 was very successful; it should be noted that this study was conducted after earlier research stays in the Gidraland for long periods beginning in the late 1960s.

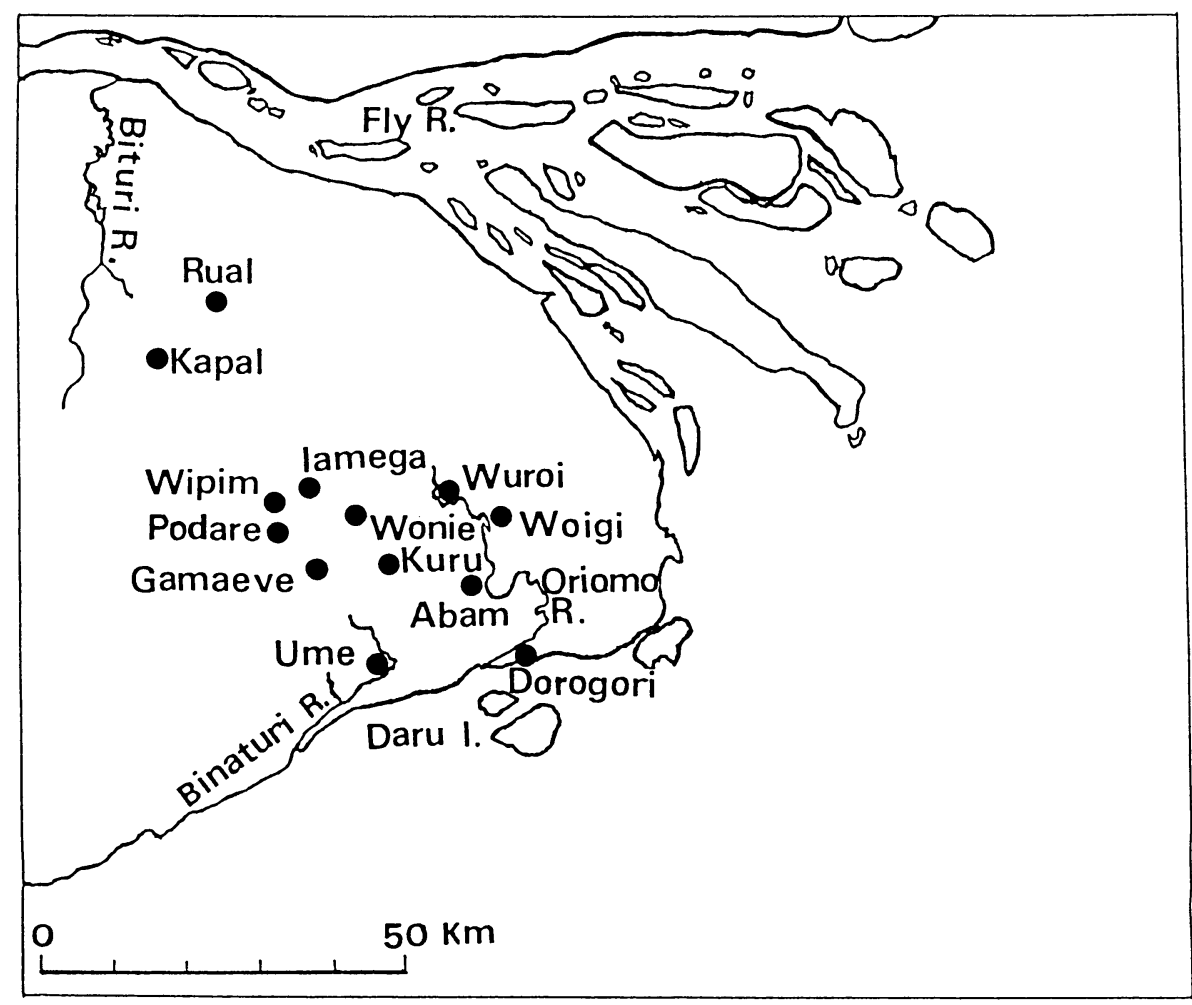

Fig. 1. The location of the 13 Gidra-speaking villages in the lowlands of Papua New Guinea, located approximately between $142^{\circ} 45^{\prime}$ and $143^{\circ} 30^{\prime}$ east longitude and between $8^{\circ} 15^{\prime}$ and $9^{\circ}$ south latitude. 
The data from this study and their implications have already been reported (Ohtsuka, 1986): for instance, the estimated annual population increase rate among the Gidra in the period with negligible modernization influences, i.e., before 1950, was $0.2 \%$ on average; there were large differences among village groups, that is, a highly positive increase rate in the inland village group and a negative rate in the riverine one. Here I will discuss two additional implications based on these findings.

\section{Ethnohistorical implications}

The inter-village group difference in population increase rate in the past has provided a good measure for the Gidra people's survival history. The oral traditions of the Gidra say that their original settlement was located in the westernmost part of the present Gidraland (cf. Fig. 1), that the clan ancestors exclusively inhabited the inland area, and that migrations to the riverine areas took place later (Ohtsuka, in press). Taking into account the higher rate of malarial infections in the riverine environment (Nakazawa et al., forthcoming) and the higher availability of animal protein sources in the inland zone in the period before approximately 1950 (Ohtsuka, 1993), their ethnohistory can be summarized as follows: in the early stage, the Gidra adapted to the inland area, and then, as they experienced population pressure owing to their gradual increase in numbers, some were obliged to migrate to more vulnerable riverine environments.

The reconstruction of the Gidra's long-term survival history, with the aid of the different NRR values in their environments, provides us a good tool for considering the reasons why most human populations have inhabited heterogeneous environments, including vulnerable ones for survival. At a minimum, it can be said that ethnohistory, which is usually reconstructed according to oral traditions, is confirmed by quantified indicators when the genealogical-demographic method is applied.

\section{Population genetic implications}

Population geneticists have considered the marriage formation system as an important factor conditioning gene frequencies of a contemporary population (e.g., Dyke, 1971; Leslie, 1985; Serjeantson et al., 1989). Also important in understanding gene frequencies are inter-individual differences in the number of childbearings more precisely, the number of offspring (both males and females) who survived to marry per mother or father.

The Gidra genealogical-demographic study has revealed that the number of married offspring markedly varies from one woman to another. In Table 2, which shows the distribution of mothers and fathers according to the number of their offspring who have married, we can observe large variabilities, which imply that individual genetic traits transmitted through generations tend to vary a great deal. 
This is exemplified by our simulation analysis to stochastically calculate the number of offspring who are descendants of the founders (the mothers and fathers at the initial generation) over generations, under the conditions that (1) males and females in the initial generation number respectively 100, (2) all of them marry once, and (3) the number of their married offspring follows the empirically observed mothers' distribution; each individual's number of offspring is randomly decided. The results prove that at the 10th generation, 153.2/200 founders have had no descendant, and the others are distributed widely from 1 to 84 descendants according to a distribution pattern of decrease toward the larger number of offspring.

Table 2. The per cent distributions of mothers $(\mathrm{N}=477)$ and fathers $(\mathrm{N}=492)$ of the initial generation, according to the number of their offspring who survived to marry

\begin{tabular}{|c|c|c|}
\hline $\begin{array}{l}\text { No. of married } \\
\text { children }\end{array}$ & No. of mothers $(\%)$ & No. of fathers (\%) \\
\hline 0 & $134(28.1)$ & $138(28.0)$ \\
\hline 1 & $96(20.1)$ & $101(20.5)$ \\
\hline 2 & $67(14.0)$ & $84(17.1)$ \\
\hline 3 & $63(13.2)$ & $54(11.0)$ \\
\hline 4 & $48 \quad(10.1)$ & $50(10.2)$ \\
\hline 5 & $38 \quad(8.0)$ & $28 \quad(5.7)$ \\
\hline 6 & $14 \quad(2.9)$ & $16 \quad(3.3)$ \\
\hline 7 & $12 \quad(2.5)$ & $9 \quad(1.8)$ \\
\hline 8 & $4 \quad(0.8)$ & $2(0.4)$ \\
\hline 9 & $1 \quad(0.2)$ & $3(0.6)$ \\
\hline 10 & 0 & $3(0.6)$ \\
\hline 11 & 0 & $1 \quad(0.2)$ \\
\hline 12 & 0 & $2(0.4)$ \\
\hline 13 & 0 & $1 \quad(0.2)$ \\
\hline
\end{tabular}

This kind of demographic information is helpful in considering the gene frequencies of current populations and their inter-generational changes; for the Gidra, we have examined the gene frequencies for more than 20 markers for a large number of blood samples collected in 1989, and thus can examine the effects of the large individual variation in reproductive rates on their genetic structure. In a broader sense, genetic and ecological (including demographic) structures will contribute to a better understanding of human population biology or human population ecology, as has been propounded by, for instance, Little and Haas (1989), Ohtsuka and Suzuki (1990), and Lomnicki (1988).

\section{CONCLUDING REMARKS}

For elucidating long-term human survival rates at the population level, this paper has discussed the methodological implications of genealogy-based reconstruction of 
reproduction rates and population increase rates in the past, based on my own study among the Gidra population. The application of the same method to several other Papua New Guinea populations in less developed areas has not met with success, however, largely because it was difficult to obtain reliable information about their genealogies and vital events. There were two major reasons for this. First, the populations studied do not have social systems which have forced the people to memorize their ancestors' marriages and births. Second, some populations maintained a semi-nomadic lifestyle until the recent past, so their memories of genealogies were fairly poor.

The applicability of the method discussed in this paper has some limitations. It is also the case, however, that the findings among the Gidra population can contribute to elucidating various aspects of their long-term survival system. Thus, the application of this method to other populations is still needed, and the development of new methods is also expected in ecological field work among humans at a population level.

\section{ACKNOWLEDGEMENTS}

The field work in the Gidra-speaking villages, on which this paper was based, was financially supported by Monbusho International Scientific Research Program; I thank the Gidra people for their kind cooperation. Financial aid of the Grant-inAid for Cooperative Research from the Ministry of Education, Science and Culture made possible to prepare this paper; discussion with many colleagues in this project was also indispensable.

\section{REFERENCES}

Dobzhansky, T. (1968) Adaptedness and fitness. In Population Biology and Evolution (Lewontin, R.C., ed.), Syracuse Univ. Press, New York, pp. 109-121.

Dyke, M. (1971) Potential mates in a small human population. Soc. Biol. 18, 28-39.

Ellen, R. (1982) Environment, Subsistence and System: The Ecology of Small-Scale Formations, Cambridge Univ. Press, Cambridge.

Howell, N. (1979) Demography of Dobe !Kung, Academic Press, New York.

Inaoka, T. (1994) Evaluation of nutritional adaptation in the field: An application of filter paper method for urinalysis. Anthropol. Sci. 102, 39-47.

Kuchikura, Y. (1994) Methods and problems in the food consumption surveys of Papua New Guinea populations. Anthropol. Sci. 102, 23-38.

Leslie, P.W. (1985) Potential mates analysis and the study of human population structure. Yearbook Phys. Anthropol. 28, 53-78.

Little, M.A., and Haas, J.D., eds. (1989) Human Population Biology: A Transdisciplinary Science, Oxford Univ. Press, New York.

Lomnicki, A. (1988) Population Ecology of Individuals, Princeton Univ. Press, Princeton.

Moran, E.F., ed. (1990) The Ecosystem Approach in Anthropology: From Concept to Practice, Univ. of Michigan Press, Ann Arbor. 
Nag, M. (1962) Factors Affecting Human Fertility in Nonindustrial Societies: A Cross-Cultural Study, Yale University Publications in Anthropology No. 66, Yale Univ. Press, New Haven.

Nakazawa, M., Ohtsuka, R., Kawabe, T., Hongo, T., Suzuki, T., Inaoka, T., Akimichi, T., Kano, S., and Suzuki, M. (forthcoming) Differential distribution of antimalarial antibody titers among villages of the Gidra in Papua New Guinea. Trop. Geogr. Med. (submitted)

Odum, E.P. (1971) Fundamentals of Ecology, 3rd Ed., W.B. Saunders, Philadelphia.

Ohtsuka, R. (1983) Oriomo Papuans: Ecology of Sago-Eaters in Lowland Papua, Univ. of Tokyo Press, Tokyo.

Ohtsuka, R. (1986) Low rate of population increase rate of the Gidra Papuans in the past: A genealogical-demographic analysis. Am. J. Phys. Anthropol. 71, 13-23.

Ohtsuka, R. (1993) Changing food and nutrition of the Gidra in lowland Papua New Guinea. In Tropical Forests, People and Food: Biocultural Interactions and Applications to Development (Hladik, C.M., Hladik, A., Linares, O.F., Pagezy, H., and Hadley, M., eds.), UNESCO, Paris, pp. 257-269.

Ohtsuka, R. (in press) The adaptation of the Gidra-speaking population in Papua New Guinea. In Beyond Nature and Culture (Ellen, R.F., and Fukui, K., eds.), Berg, Oxford.

Ohtsuka, R., and Suzuki, T., eds. (1990) Population Ecology of Human Survival: Bioecological Studies of the Gidra in Papua New Guinea, Univ. of Tokyo Press, Tokyo.

Pressat, R. (1985) Net reproduction rate (NRR). In The Dictionary of Demography (Wilson, C., ed.), Basil Blackwell, Oxford, pp. 160-161.

Rappaport, R.A. (1990) Ecosystems, populations and people. In The Ecosystem Approach in Anthropology: From Concept to Practice (Moran, E.F., ed.), Univ. of Michigan Press, Ann Arbor, pp. $41-72$.

Serjeantson, S.W., Board, P.G., and Bhatia, K.K. (1989) Population genetics in Papua New Guinea: A perspective on human evolution. In Human Biology in Papua New Guinea (Attenborough, R.D., and Alpers, M.P., eds.), Clarendon, Oxford, pp. 198-233.

Suda, K. (1994) Methods and problems in time allocation studies. Anthropol. Sci. 102, 13-22.

Suzuki, T., and Ohtsuka, R., eds. (1987) Human Ecology of Health and Survival in Asia and the South Pacific, Univ. of Tokyo Press, Tokyo. 